\title{
PREFACE TO THE SPECIAL ISSUE ON RESTORATION AND RECOVERY FROM THE 2011 GREAT EAST JAPAN EARTHQUAKE
}

The 2011 off the Pacific Coast of Tohoku Earthquake that occurred on March 11 brought serious damage to the infrastructure facilities in Tohoku and Kanto districts owing to the strong earthquake motion, tsunami, and nuclear power plant accident. This was referred to as "triple disasters" by a newspaper and was given the name the "Great East Japan Earthquake Disaster" by Cabinet decision.

Five years has passed since this disaster occurred. During these five years, restoration works in affected areas have progressed steadily with the aim to make a strong community that is resilient to disaster and restore local life and economic activity. In these activities, civil engineering plays an important role. In particular, the Japan Society of Civil Engineers (JSCE) is considered very important in providing the technical and scientific knowledge necessary for these activities to international societies.

In this regard, the JSCE has come out with the second special issue on the Great East Japan Earthquake Disaster. This issue is a valuable collection of papers and reports on various recovery efforts and technological development to achieve the recovery works. Sixteen invited papers and seven general papers are included in this issue. The JSCE takes pride in editing and publishing this second special issue on the Great East Japan Earthquake Disaster. The technical and scientific knowledge and other information on the restoration and recovery works from the natural disaster contained in this issue will be useful for other countries that similarly suffered from earthquake disaster. On behalf of the editorial committee, I wish to sincerely thank the authors, reviewers, and all of the contributors in this special issue.

Guest Editor-in-Chief for the Special Issue Motoki Kazama, Tohoku University

\section{Guest Editors for the Special Issue}

Susumu Nakamura, Nihon University

Norimi Mizutani, Nagoya University

Katsuya Hirano, Tohoku University

Ichiro Iwaki, Nihon University

Shin-ei Takano, Hokkaido University

Tatsuo Omura, Tohoku University 